\title{
Exosomal p38 Mitogen-activated Protein Kinase Promotes Tumour Repopulation in TP53-mutated Bile Duct Cancer Cells
}

\author{
MAMI OSAWA ${ }^{1}$, YASUNOBU MATSUDA ${ }^{2}$, JUN SAKATA ${ }^{1}$ and TOSHIFUMI WAKAI ${ }^{1}$ \\ ${ }^{1}$ Division of Digestive and General Surgery, \\ Niigata University Graduate School of Medical and Dental Sciences, Niigata, Japan; \\ ${ }^{2}$ Department of Medical Technology, Niigata University Graduate School of Health Sciences, Niigata, Japan
}

\begin{abstract}
Background/Aim: Tumour repopulation is a major obstacle for successful cancer treatment. This study investigated whether anticancer agents contribute to tumour repopulation in TP53-mutated bile duct cancer cells. Materials and Methods: TP53-mutated HuCCT1 and HuH28 cells were exposed to anticancer agents, and recipient cells were exposed to their conditioned media or exosomes. The effect of inhibitors and siRNA-mediated gene silencing of p38 mitogen-activated protein kinase (MAPK) and of TP53 was analyzed by cell proliferation assays and western blotting. Results: Conditioned media from genotoxic agent-treated cells promoted proliferation of recipient cells $(p<0.05)$, and this effect was abrogated by exosome inhibitors. Exosomes from gemcitabine- or cisplatintreated cells increased cell proliferation by 1.6- to 2.2-fold $(p<0.05)$ through $p 38$ MAPK signalling. These effects of exosomes were inhibited by inhibition/silencing of p38 MAPK but not by TP53 silencing. Conclusion: Exosomal p38 MAPK plays a pivotal role in tumour repopulation in a TP53independent manner.
\end{abstract}

Tumour recurrence after chemoradiotherapy is one of the leading causes of death among patients with advanced cancer. A major critical issue in cancer treatment is the rapid and excessive proliferation of residual tumour cells after therapy, which has been described as tumour repopulation (1, $2)$. In the clinical setting, chemotherapy and radiotherapy are often administered over several cycles to allow healthy cells to recover. Such protocols might accelerate tumour cell

This article is freely accessible online.

Correspondence to: Yasunobu Matsuda, MD, Department of Medical Technology, Niigata University Graduate School of Health Sciences, 2-746 Asahimachi-dori, Chuo-Ku, Niigata 951-8518, Japan. Tel: +81 252270958, Fax: +81 252270749, e-mail: yasunobu@med.niigata-u.ac.jp

Key Words: p38 MAPK, TP53, tumour repopulation, exosomes, bile duct cancer. proliferation during treatment withdrawal (3) but the underlying mechanism of tumour repopulation is unclear. Bile duct cancer (BDC) is a relatively rare malignancy with a poor prognosis that develops from the intra- or extra-hepatic bile ducts. Surgical resection is the only curative treatment for $\mathrm{BDC}$; however, recurrence after resection is common, and more than two-thirds of lesions are unresectable (4). Treatment with the nucleotide analogue gemcitabine, alone or in combination with cisplatin, is considered the standard first-line chemotherapy in advanced BDC (5). Unfortunately, the therapeutic effect of gemcitabine is marginal and the causal mechanism of tumour recurrence after gemcitabine treatment is unclear.

Accumulating evidence indicates that dying cells release a bioactive secretome consisting of a diverse range of mitogens and extracellular vesicles including exosomes, which induce compensatory proliferation in adjacent living cells $(6,7)$. Compensatory proliferation is well preserved from metazoan to mammalian species, and it is involved in tissue repair processes and tumour development (8-10). For example, in the proliferating tissues of eyes or wing of Drosophila, the initiator caspase Dronc activates the tumour suppressor TP53 and stress kinase c-JUN amino-terminal kinase (JNK) in apoptotic cells. This signal transduction cascade activates the release of mitogens including Wingless (analogue Wnt), Decapentaplegic (a member of the $\beta$-transforming growth factor family) and $\mathrm{NOTCH}$, thus inducing compensatory proliferation $(7,11,12)$. Although there is limited research on the molecular mechanism of dying cellmediated cell proliferation in human cancer, a recent study reported that caspase-3-mediated ataxia telangiectasia mutated (ATM)/TP53/cyclo-oxygenase-2/prostaglandin $\mathrm{E}_{2}$ signalling contributes to radiation-induced tumour repopulation in nonsmall cell lung cancer cells (13). It is therefore highly likely that the caspase-TP53 axis is a key player in tumour repopulation following chemoradiotherapy.

We sought to determine whether mechanisms other than caspase-TP53 signalling are involved in tumour repopulation because TP53 is the most representative tumour-suppressor gene and is mutated in approximately half of all human cancer cases. Histological and genomic profiling analyses of BDC 
revealed that TP53 is the most frequently (23-52\%) mutated driver gene (14-16). TP53 mutation enhances gemcitabine resistance (16), and is significantly correlated with poorer prognosis in BDC (14). The underlying mechanism of tumour repopulation in TP53-mutated cells has not been clarified. Considering the poor survival of patients with BDC, it might be useful to examine whether tumour repopulation contributes to the weaker effect of chemotherapy in TP53-mutated BDC.

In this study, we examined whether treatment with anticancer agents, including gemcitabine, caused tumour repopulation in TP53-mutated BDC cells. With this aim, in vitro conditioned medium transfer experiments (17-19) were used to mimic the biological process of chemotherapyinduced tumour cell proliferation. The aims of the study were to elucidate the molecular target of tumour repopulation in TP53-mutated BDC cells and identify an effective method to overcome the weak effect of chemotherapy in BDC.

\section{Materials and Methods}

Cell culture. TP53-mutated gemcitabine-sensitive HuCCT1 [Arg175 to His [R175H]; a gain-of-function phenotype of mutant TP53 (20)] and gemcitabine-resistant $\mathrm{HuH} 28$ [Glu271 to Lys [E271K]; inactive mutation (21)] human BDC cells (22) (IARC TP53 Database; https://p53.iarc.fr/CellLines.aspx) were obtained from Japanese Collection of Research Bioresources Cell Bank (Osaka, Japan). Cells were cultured in Roswell Park Memorial Institute-1640 culture medium supplemented with sodium pyruvate and $10 \%$ heat-inactivated fetal bovine serum in humidified incubator at $37^{\circ} \mathrm{C}$ with $5 \% \mathrm{CO}_{2}$. To analyze cell morphology, cultured cells were fixed and stained with Giemsa.

Reagents. Gemcitabine (Santa Cruz Biotechnology, Santa Cruz, Dallas, TX, USA) was dissolved in phosphate-buffered saline. Cisplatin (Merck Millipore, Darmstadt, Germany) was solubilized in $0.9 \%$ sodium chloride with water bath sonication. Sorafenib (Toronto Research Chemicals, Downsview, ON, Canada) and regorafenib (Santa Cruz Biotechnology) were dissolved in dimethyl sulfoxide (DMSO). The final concentration of anticancer agents was set at close to the $50 \%$ inhibitory concentration obtained in preliminary experiments, which was defined as the concentration of drugs required for $50 \%$ cell survival after $48 \mathrm{~h}$ of treatment. Consequently, the final concentrations of gemcitabine, cisplatin, sorafenib and regorafenib were set at 1, 40, 20 and $10 \mu \mathrm{M}$, respectively, for HuCCT1 cells and 5, 50, 20 and $20 \mu \mathrm{M}$, respectively, for $\mathrm{HuH} 28$ cells.

Z-VAD-FMK (a cell permeable pan-caspase-specific inhibitor; Enzo Life Sciences, Farmingdale, NY, USA), LY294002 (an inhibitor of phosphoinositide 3-kinase/AKT serine/threonine kinase 1; Cell Signaling Technology, Beverly, MA, USA), SB203580 [an inhibitor of p38 mitogen-activated protein kinase (MAPK); Enzo Life Sciences], BMS-582949 (an inhibitor of p38 MAPK; Cayman Chemical, Ann Arbor, MI, USA), SP600125 (an inhibitor of JNK; Enzo Life Sciences), U0126 (an inhibitor of MAPK kinase 1/2; Merck Millipore), KU55933 (an inhibitor of ATM; Merck Millipore), schisandrin B [an inhibitor of ataxia telangiectasia and RAD3-related (ATR); LKT Laboratories, St. Paul, MN, USA], GW4869 [a neutral sphingomyelinase (N-SMase) inhibitor; Merck Millipore] and spiroepoxide ( $N$-SMase inhibitor; Santa CruzSanta Cruz Biotechnology) were dissolved in DMSO and used at concentrations of $20,25,20,5,50,10,10,30,10$, and $10 \mu \mathrm{M}$, respectively. $N$ Acetyl-1-cysteine (NAC, LKT Laboratories) was freshly prepared by dissolving in water at $\mathrm{pH} 7.4$ and used at $5 \mathrm{mM}$. In all experiments, cells were pretreated with chemical inhibitors for $2 \mathrm{~h}$ before treatment with anticancer agents. The final concentration of DMSO was set at $0.1 \%$ as a solvent control.

Conditioned medium transfer. Donor cells $\left(1 \times 10^{6}\right.$ cells $\left./ \mathrm{ml}\right)$ were treated with anticancer drugs with or without chemical inhibitors at the aforementioned concentrations for $24 \mathrm{~h}$. Thereafter, cells were washed three times with fresh medium to remove non-adherent cells. After $2 \mathrm{~h}$ of culture, cells were again washed three times with fresh medium to remove remaining drugs in the cellular environment and maintained in growth medium for an additional $24 \mathrm{~h}$. Samples of conditioned media were then collected, centrifuged at $300 \times g$ for 10 min to remove cell debris, and transferred to naïve recipient cells $\left(0.5 \times 10^{5}\right.$ or $2.5 \times 10^{5}$ cells $\left./ \mathrm{ml}\right)$ grown separately. Recipient cells were cultured with the donor-derived conditioned media for 2 or $48 \mathrm{~h}$.

Small interfering RNA (siRNA) transfection. Transient transfection reaction was conducted in cultured cells $\left(2.5 \times 10^{5}\right.$ cells $\left./ \mathrm{ml}\right)$ using siRNA using HiPerFect reagent (Qiagen, Hilden, Germany) according to the manufacturer's protocol. To silence the p38 MAPK gene, cells were transfected with either $30 \mathrm{nM}$ prevalidated Mission siRNA directed against p38 MAPK (ID number: SASI_Hs01_00018467; Merck Millipore) or Mission siRNA Universal Negative Control (Merck Millipore). To silence the TP53 gene, $50 \mathrm{nM}$ validated TP53 siRNA pool (sc-29435; Santa Cruz Santa Cruz Biotechnology) or its negative control was used. The silencing efficiency of siRNA was validated by western blotting. After $48 \mathrm{~h}$ of transfection, the medium was replaced with fresh medium, and the cells were treated with gemcitabine. To obtain exosomes, cells were washed after $24 \mathrm{~h}$ and cultured for an additional $24 \mathrm{~h}$. Exosomes were then purified from the conditioned media.

Exosome isolation. Samples of conditioned medium were obtained as described above and centrifuged at $10,000 \times \mathrm{g}$ for $30 \mathrm{~min}$. Exosome samples were concentrated using a Vivaspin 20 ultrafiltration unit (Sartorius, Edgewood, NJ, USA) and purified by a MagCapture Exosome Isolation Kit PS (Fujifilm Wako Pure Chemical Corporation, Tokyo, Japan) as previously reported (23). The protein content of purified exosomes was analyzed by BCA assay (Pierce Biochemical, Rockford, IL, USA) and calculated using three different isolations in each experiment. The morphology of the exosomes was characterized using a field emission transmission electron microscope (JSM-7500F; JEOL Ltd., Japan), and the size distributions were analyzed by NanoSight technology (NanoSight LM10; Malvern Instrument, Amesbury, UK). Exosomes were sterilized through $0.22-\mu \mathrm{m}$ capsule filters and added to the cells at a concentration of $40 \mu \mathrm{g} / \mathrm{ml}$ from $5 \mathrm{~min}$ to $48 \mathrm{~h}$.

Cell proliferation assay. Recipient cells $\left(0.5 \times 10^{5}\right.$ cells $\left./ \mathrm{ml}\right)$ were seeded overnight in 96-well plates and cultured for $48 \mathrm{~h}$ after treatment with anticancer agents or exosomes. Cell proliferation was examined using a Cell Counting Kit WST-8 (Dojindo Laboratories, Kumamoto, Japan) according to the manufacturer's instructions. The absorbance at $450 \mathrm{~nm}$ was detected by a MULTISKAN FC microtiter-plate reader (Thermo Fisher Scientific, Vantaa, Finland). Cell viability was evaluated using the trypan blue exclusion assay as reported (24). In all experiments, the results were obtained from three independent procedures. 
Western blotting. Cells or exosomes were lysed in RIPA buffer (Invitrogen, CA, USA) supplemented with complete protease inhibitor, and the protein content was quantified using a BCA Protein Assay kit (Invitrogen). Equivalent amounts of protein $(20 \mu \mathrm{g})$ were separated by $10 \%$ sodium dodecyl sulfate-polyacrylamide gel electrophoresis and transferred onto immobilon-P polyvinylidene difluoride membranes. To analyze cell signalling, the following primary antibodies were used (all from Cell Signaling Technology): Rabbit polyclonal antibody against p38 MAPK (\#9212) and rabbit monoclonal antibodies against p-p38 MAPK (Thr180/Tyr182, D3F9), p-MAPK-activated protein kinase 2 (MAPKAPK2, alias MK2; Thr334, 27B7), p-AKT (Thr308, D25E6), pNF-kB p65 (Ser536, 93H1), p-ATM (Ser1981), and p-ATR (Ser428). Exosome/cytosol markers were evaluated using mouse monoclonal antibody against programmed cell death 6 interacting protein (PDCD6IP, alias Alix) (clone 3A9; Cell Signaling Technology) and polyclonal antibodies against CD63 (Santa Cruz Biotechnology) and calnexin (Cell Signaling Technology). A mouse monoclonal TP53 antibody (clone DO1) which reacts with $T P 53-\mathrm{R} 175 \mathrm{H}$ was obtained from Santa Cruz Biotechnology (25), and a mouse monoclonal antibody against $\beta$-actin was obtained from Sigma-Aldrich (St Louis, MO, USA). Following the reaction with horseradish peroxidase-conjugated secondary antibodies, blot signals were observed using an enhanced ECL Western blotting detection system (Cytiva, Uppsala, Sweden). Protein band intensity normalized by $\beta$-actin band was quantified using image analysis software (ImageJ, ver. 1.44; NIH, Bethesda, MD, USA).

Statistical analysis. Significant differences between two groups were evaluated using a two-tailed Student's $t$-test. Bar graphs present the means, and error bars represent the standard deviation. Differences with $p<0.05$ were considered statistically significant.

\section{Results}

Conditioned media from cells treated with genotoxic reagents induced cell proliferation. Recipient HuCCT1 and $\mathrm{HuH} 28$ cells were incubated with conditioned media from donor cells, which were pretreated with several anticancer agents. In all experiments, the proportion of trypan bluepositive dead cells was $20-30 \%$ for donor cells and less than $3 \%$ for recipient cells (not shown). The results of WST assays illustrated that the culture media from donor cells treated with gemcitabine or cisplatin significantly increased the proliferation of naïve recipient cells by 1.7 - to 2.1 -fold versus the growth of cells grown in control medium as indicated by the optical density at $450 \mathrm{~nm}(p<0.05)$. Conditioned media from cells treated with either sorafenib or regorafenib did not induce cell proliferation (Figure 1).

Cell proliferation in conditioned media was caused by oxidative stress-induced p38 MAPK. When donor cells were pretreated with the pan-caspase inhibitor Z-VAD-FMK, cell proliferation was relatively but not significantly inhibited after incubation with conditioned media from cells treated with gemcitabine or cisplatin, excluding the significant difference in HuCCT1 cell growth after incubation in conditioned medium from cisplatin-treated cells $(p<0.05)$. By contrast, when donor cells were pretreated with NAC before treatment with genotoxic agents, the effects of conditioned media from cells treated with gemcitabine or cisplatin were significantly reduced (without NAC $v s$. with NAC, HuCCT1: both $p<0.01$; HuH28: $p<0.05$ and $p<0.01$, respectively; Figure 2A).

The effects of conditioned medium from cells treated with gemcitabine on proliferation were suppressed when donor cells were pretreated with inhibitors of MAPKs or stress kinases before gemcitabine treatment. Among the inhibitors, the p38 MAPK inhibitor SB203580 most strongly suppressed cell proliferation, which was comparable to that of donor cells treated with the antioxidant NAC (without $v s$. with SB03580, $p<0.01$ for both cell lines; Figure 2B). Western blotting demonstrated that the phosphorylation of p38 MAPK was increased by gemcitabine treatment to 6- to 9-fold and 12- to 16-fold of controls in HuCCT1 and HuH28 cells, respectively (both $p<0.05$ vs. control). Gemcitabine-induced phosphorylation was suppressed by pretreatment with NAC ( $p<0.05$ in both cell lines; Figure $2 \mathrm{C}$ ), indicating that p38 MAPK is activated by oxidative stress.

Genotoxic agent-induced cell proliferation is mediated by extracellular vesicles. In this study, we investigated the involvement of extracellular vesicles in genotoxic agentinduced tumour cell proliferation. The results of western blotting confirmed that exosomes purified from HuCCT1 cells were ALIX- and CD63-positive but calnexin-negative (Figure 3A). Transmission electron micrographs revealed no significant morphological differences between exosomes from control and gemcitabine-treated cells (Figure 3B). Similarly, NanoSight nanoparticle analysis demonstrated that these exosomes had similar size distributions (mean \pm standard deviation: $118 \pm 1.4$ vs. $129 \pm 2.4 \mathrm{~nm}$, Figure 3C). The effects on cell proliferation of conditioned medium from cells treated with gemcitabine were significantly inhibited by pretreatment with either GW4869 or spiroepoxide (both $p<0.05$; Figure 3D). In both HuCCT1 and $\mathrm{HuH} 28$ cells, treatment with exosomes from either gemcitabine-treated or cisplatin-treated cells increased proliferation by 1.6- to 2.2-fold (Figure 3E and F).

p38 MAPK signalling is involved in exosome-mediated cell proliferation. To investigate the functional relationship between p38 MAPK and exosomes, donor cells were pretreated with p38 MAPK inhibitors (SB203580 and BMS582949) before gemcitabine treatment. Exosomes were then purified and added to recipient cells. In both HuCCT1 and HuH28 cells, the effects of these exosomes on cell proliferation were significantly inhibited by both p38 MAPK inhibitors (all $p<0.05$; Figure 4A). To further evaluate the function of p38 MAPK, exosomes were purified from p38 MAPK siRNA-transfected HuCCT1 cells. Western blot analyses showed that p38 MAPK siRNA interference led to a significant decrease in p38 MAPK protein expression (0.2to 0.3 -fold; $p<0.05)$. The WST assay illustrated that the effects of exosomes from gemcitabine-treated cells on cell 
A

HuCCT1

$\mathrm{HuH} 28$

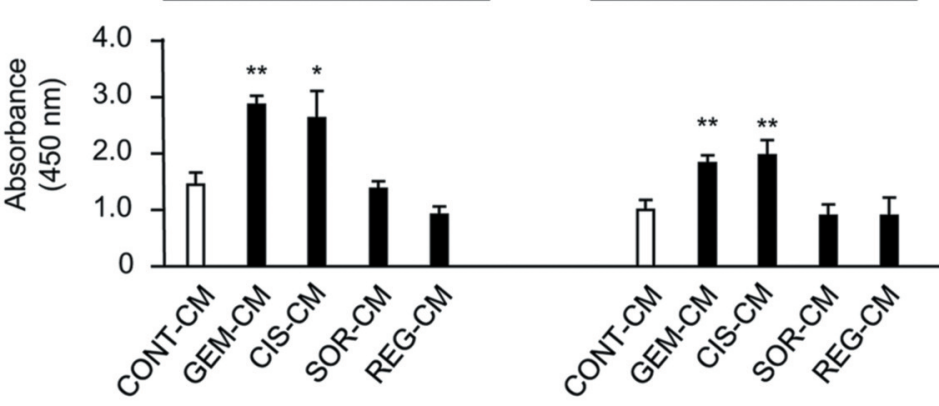

B

HuCCT1

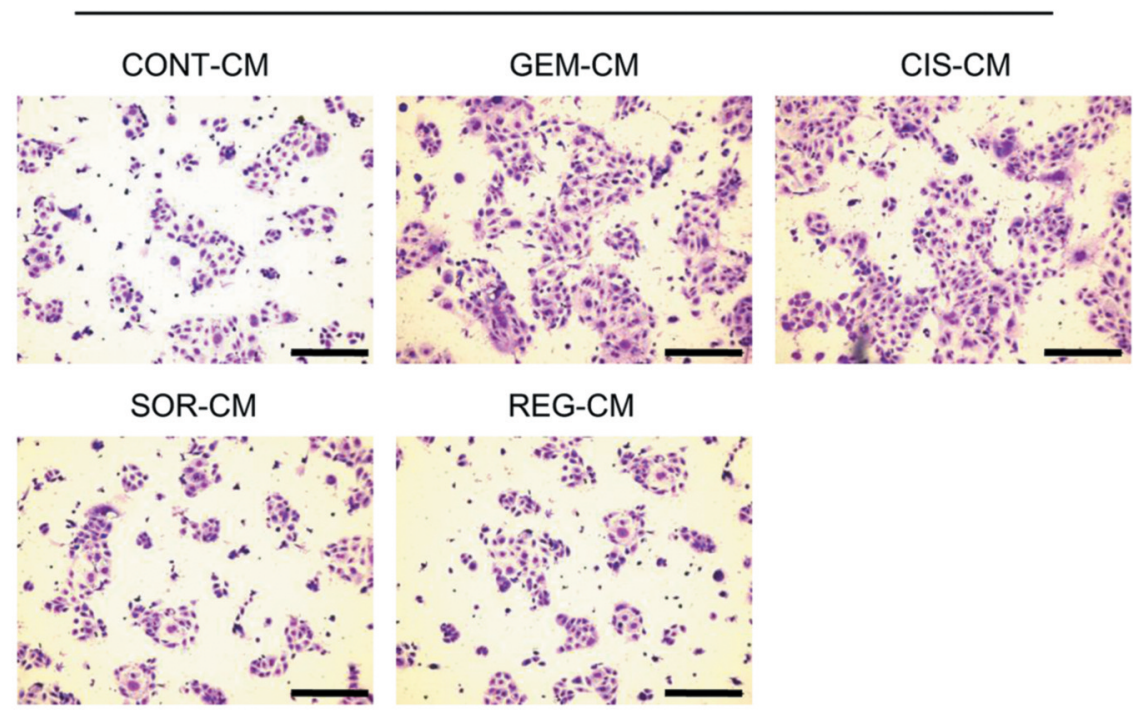

$\mathrm{HuH} 28$
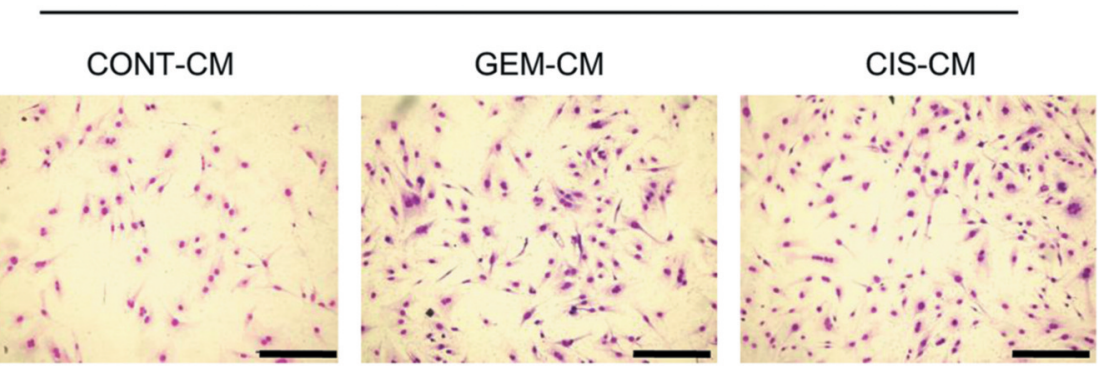

SOR-CM

REG-CM
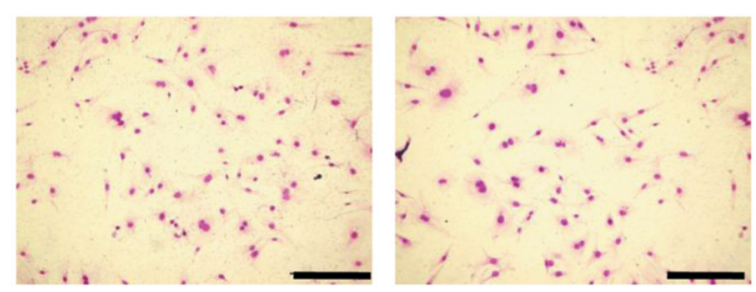

Figure 1. Conditioned media of TP53-mutated cells induce cell proliferation following treatment with genotoxic anticancer agents. A: WST assay of recipient $\mathrm{HuCCT1}$ and $\mathrm{HuH} 28$ cells. Recipient cells $\left(0.5 \times 10^{5} \mathrm{cells} / \mathrm{ml}\right.$ in 96 -well culture plates $)$ were cultured with conditioned media (CM) from control (CONT), or gemcitabine-(GEM), cisplatin-(CIS), sorafenib- (SOR), or regorafenib (REG)-treated donor cells and allowed to grow for $48 \mathrm{~h}$. Columns represent the mean optimal density $(O D)$ at $450 \mathrm{~nm}$. Data are presented as the mean \pm standard deviation of independent experiments in triplicate. Significantly different at ${ }^{*} p<0.05$ and ${ }^{* *} p<0.01$ vs. CONT-CM. B: Representative images of recipient cells stained with Giemsa (bar, $\left.300 \mu \mathrm{m}\right)$. 
A

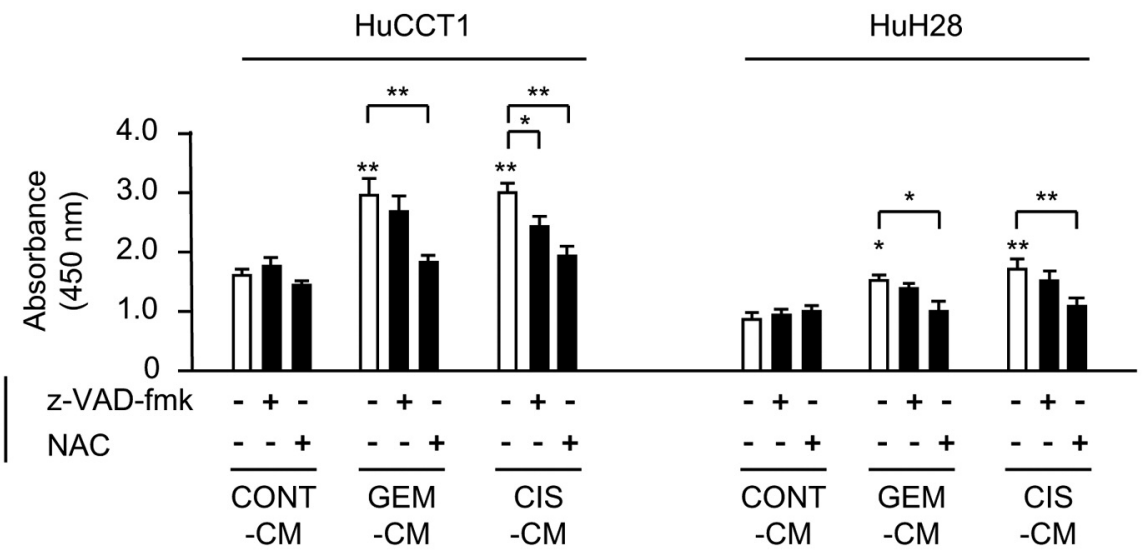

B

HuCCT1

$\mathrm{HuH} 28$

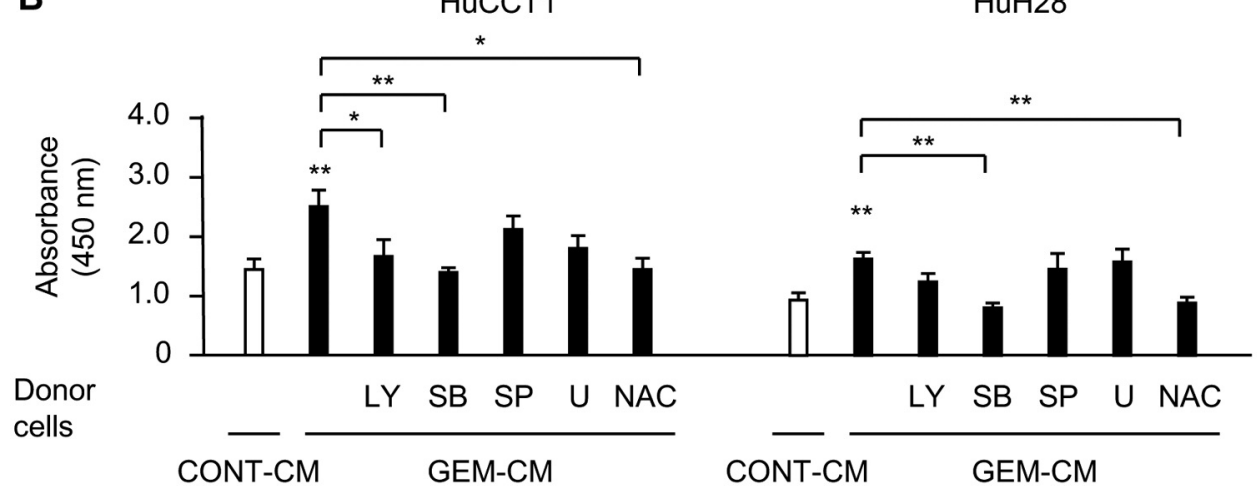

C HuCCT1 $\mathrm{HuH} 28$
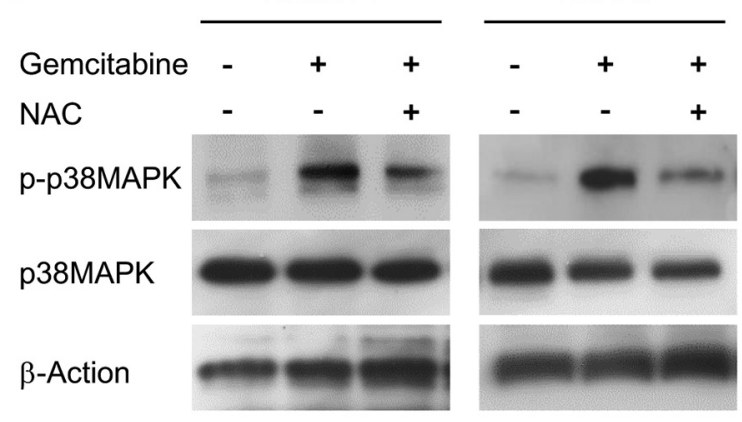

$43 \mathrm{kDa}$
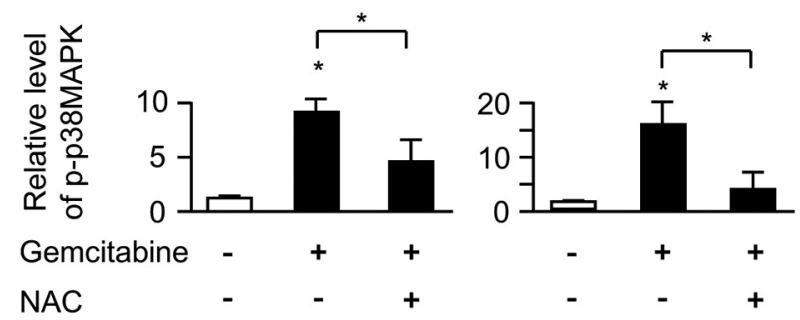

Figure 2. Effects of conditioned medium (CM) from gemcitabine (GEM)- or cisplatin (CIS)-treated cells on cell proliferation are mediated by oxidative stress and 38 mitogen-activated protein kinase (MAPK) signalling. A: WST assay of recipient cells. Donor cells were treated with genotoxic agents with or without Z-VAD-FMK (a pan-caspase-specific inhibitor) or N-acetyl-L-cysteine (NAC: a reactive oxygen species inhibitor). Recipient cells were cultured with donor cell-derived conditioned medium for $48 \mathrm{~h}$ and the optical density was then measured. B: WST assay of recipient cells. Donor cells were treated with gemcitabine for $24 \mathrm{~h}$ with or without chemical inhibitors of MAPK/stress kinases [LY294002 (LY); SB203580 (SB) SP500125 (SP), U0126N (U)], or NAC. Recipient cells were cultured for $48 \mathrm{~h}$ in the presence of each donor cell-derived CM. C: Western blot analyses of p38 MAPK expression. Cells were treated with gemcitabine for $2 \mathrm{~h}$ with or without NAC. Normalized band intensities relative to $\beta$-actin based on fold changes relative to controls are shown. Data are presented as the mean \pm standard deviation of independent experiments in triplicate. Significantly different at $* p<0.05$ and $* * p<0.01$ vs. control. p-p38 MAPK: Phospho-p38 MAPK. 


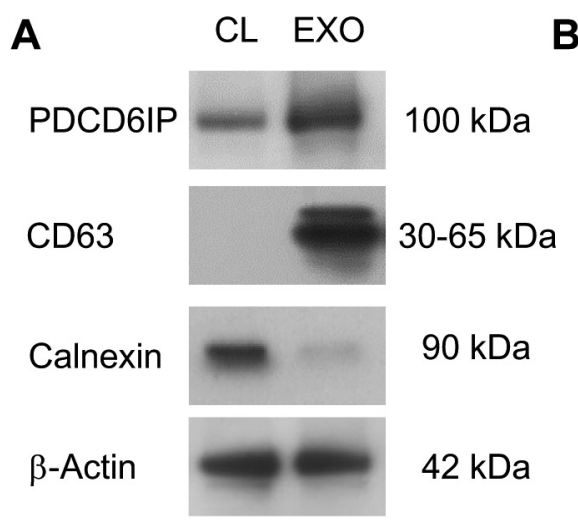

B CONT-EXO

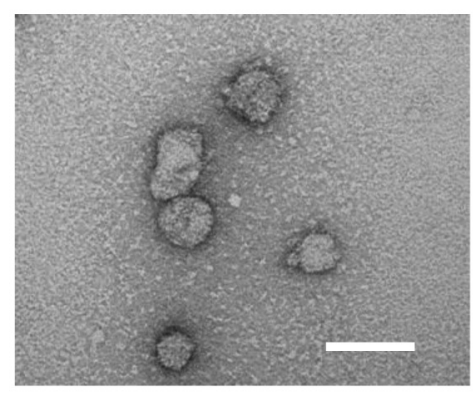

GEM-EXO

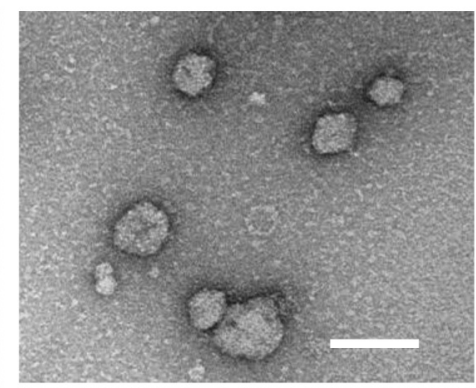

Figure 3. Continued

proliferation were significantly inhibited following p38 MAPK silencing $(p<0.05$; Figure 4B).

Exosomes carry phosphorylated p38 MAPK as cargo. Western blotting of exosomes illustrated that p-p38 MAPK expression was significantly increased by 11 - to 15 -fold in exosomes from gemcitabine-treated HuCCT1 cells compared with that in exosomes from controls $(p<0.01)$ (Figure 5A). Brief treatment (5 min) with exosomes from gemcitabine-treated cells resulted in increased p38 MAPK phosphorylation in recipient cells (4to 5-fold), which was not inhibited by SB203580 treatment ( $p>0.05$; Figure 5B). Longer treatment with these exosomes (2 h) increased p38 MAPK, MAPKAPK2, AKT, and NF-kB phosphorylation (ranging from 7- to 13-fold), and these changes were significantly suppressed when donor cells were pretreated with SB203580 ( $p<0.05$; Figure 5C).

Gemcitabine activates p38 MAPK through a TP53-independent pathway. We addressed whether the gain-of-function properties of TP53 influenced the activation of p38 MAPK. Western blot analyses showed that TP53 siRNA interference led to a significant decrease in TP53 protein expression (0.2- to 0.3-fold; $p<0.05)$. The level of gemcitabine-induced p38 MAPK phosphorylation was examined in TP53-mutated HuCCT1 cells, and no significant difference was detected between mock siRNA- and TP53 siRNA-transfected cells ( $p>0.05$ ) (Figure 6A). Moreover, the effects of exosomes from gemcitabine-treated cells on proliferation were not significantly different between mock siRNA- and TP53 siRNA-transfected cells (Figure 6B).

Gemcitabine activates p38 MAPK through oxidative stressinduced ATM-ATR signalling. In this study, we investigated the involvement of DNA-damage response and repair molecules on p38 MAPK activation in TP53-mutated cells. In both $\mathrm{HuCCT} 1$ and $\mathrm{HuH} 28$ cells, gemcitabine treatment led to a significant increase in p-ATM and p-ATR expression (ranging from 6- to 13-fold), and their phosphorylation was significantly inhibited by NAC ( $p<0.05$; Figure 7A). When cells were treated with gemcitabine in the presence of KU55933 or schisandrin B, p38 MAPK and MAPKAPK2 phosphorylation was effectively inhibited $(p<0.05$ in both cell lines) (Figure 7B).

\section{Discussion}

Tumour cell repopulation is a well-known phenomenon that has been reported as a major reason for tumour recurrence after non-operative treatment (2). Clinical data and mathematical modelling analyses suggested that the timing and speed of tumour cell repopulation are generally rapid. Tumours can repopulate to their original size within 2 weeks following lowdose chemoradiotherapy or after an extended withdrawal period after treatment (26). Such a setting may permit tumour growth to be accelerated by cancer treatment $(3,27)$.

Recent studies reported that radiation-induced dying cancer cells stimulate tumour cell proliferation mainly through caspase 3 -mediated signalling $(13,28,29)$, but few reports have described chemotherapy-induced tumour cell repopulation. To address whether tumour repopulation might be involved in the low efficacy of gemcitabine against BDC, we performed conditioned medium transfer experiments, which have been reported to reflect cell-cell interactions (17-19).

In this study, we report for the first time that gemcitabine stimulates the secretion of p38 MAPK-containing exosomes in TP53-mutated BDC cells, and these exosomes strongly induce cell proliferation. Given that the effects of these exosomes were inhibited by NAC but not Z-VAD-FMK, the cell proliferation observed in our experiments was apparently caused by DNA damage-induced oxidative stress rather than caspase-mediated signalling. We then examined whether the effects of conditioned medium from gemcitabine-treated cells on proliferation were mediated by MAPKs or stress kinases, which are the primary signalling components downstream of oxidative stress (30). Our data demonstrated 

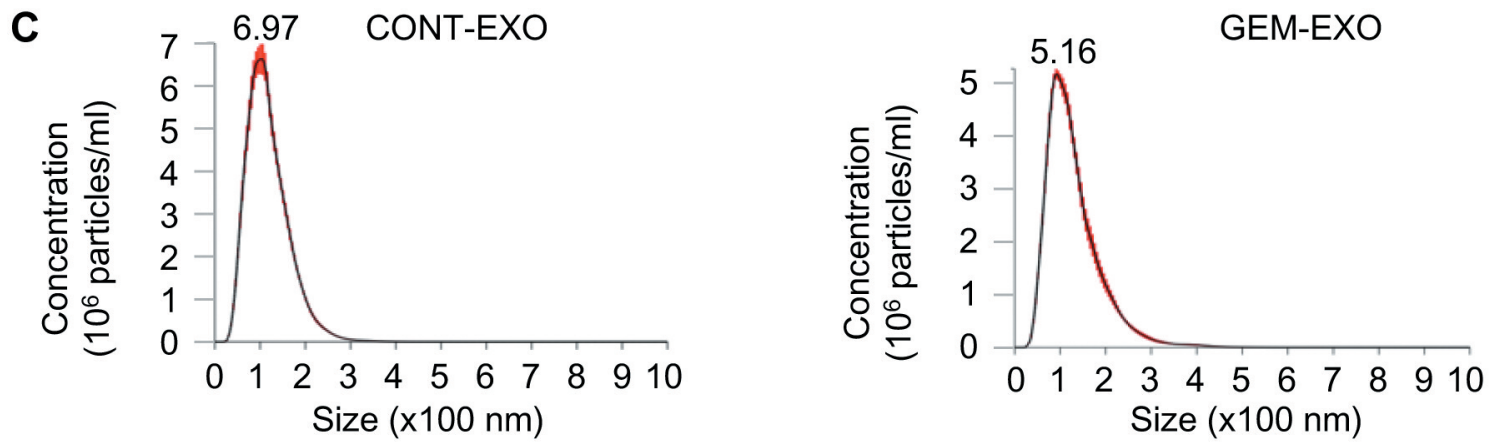

D

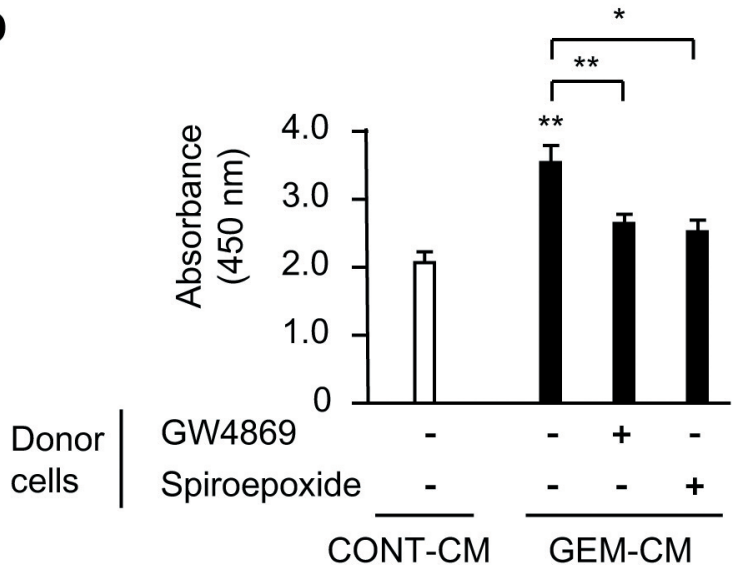

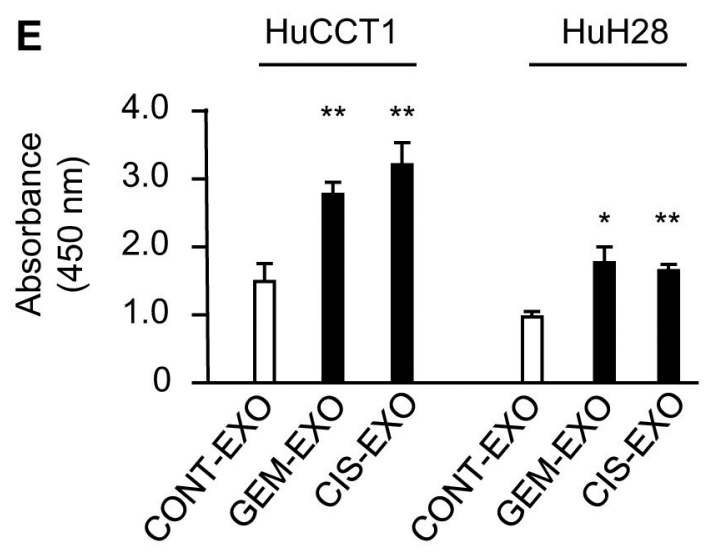

$\mathbf{F}$ CONT-EXO GEM-EXO

\section{CIS-EXO}
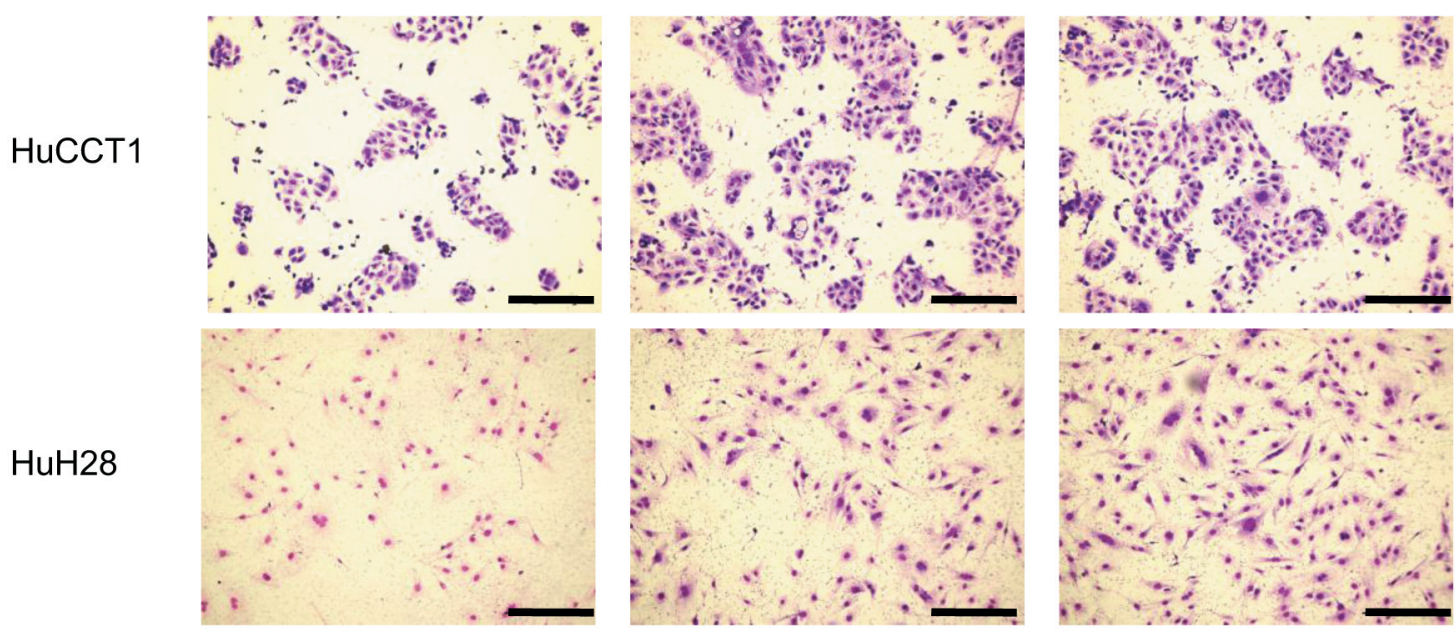

Figure 3. Exosomes derived from cells treated with gemcitabine (GEM) or cisplatin (CIS) induce cell proliferation. A: Western blot analysis of expression of programmed cell death 6 interacting protein (PDCD6IP; exosome marker), CD63 (exosome marker), and calnexin (cytosol marker) in exosomes (EXO) and cellular lysates (CL) of HuCCT1 cells. Data are representative of three independent experiments. B: Morphology of exosomes from gemcitabine-treated and control (CONT) cells observed under transmission electron microscopy (scale bar=200 nm). C: Nanoparticle tracking analysis of the isolated particles. Red error bars indicate \pm 1 standard error of the mean. Data are representative of three independent experiments. D: WST assay of recipient HuCCT1 cells. Donor cells were treated with gemcitabine for $24 \mathrm{~h}$, and conditioned medium (CM) was collected after an additional 24-h incubation with exosome inhibitors (GW4869 or spiroepoxide). Recipient cells were cultured with donor cell-derived conditioned medium for 48 h. E: WST assay of HuCCT1 and HuH28 cells after treatment with exosomes for $48 \mathrm{~h}$. F: Representative images of exosome-treated cells stained with Giemsa in three independent experiments $($ bar, $300 \mu \mathrm{m})$. Data are presented as the mean \pm standard deviation of independent experiments in triplicate. Significantly different from controls/other treatment at ${ }^{*} p<0.05$ and ${ }^{*} p<0.01$. 
A

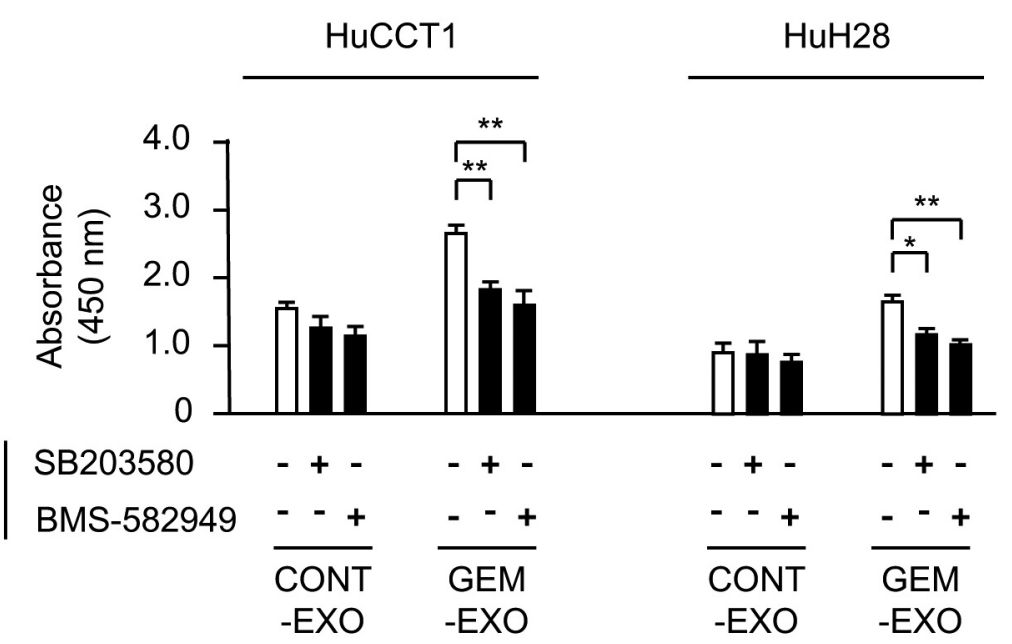

B
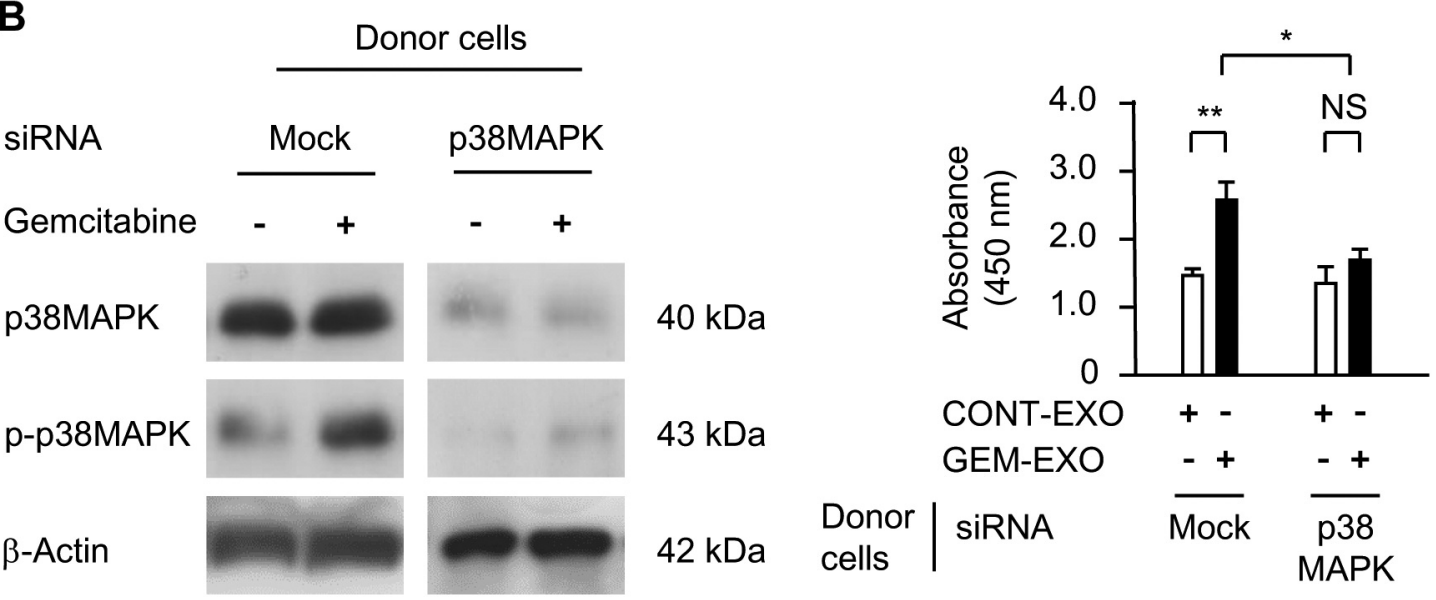

Figure 4. p38 Mitogen-activated protein kinase (MAPK) is required for the proliferation-simulating effects of exosomes from gemcitabine-treated donor cells (gemcitabine-EXO). A: WST assay of exosome-treated recipient cells. Donor cells were treated with gemcitabine for $24 \mathrm{~h}$ with or without p38 MAPK inhibitors (SB203580 and BMS-582949). Cells were washed and cultured for $24 \mathrm{~h}$, and exosomes were purified from culture medium. Recipient cells were then treated with exosomes for $48 \mathrm{~h}$. B: Silencing of p38 MAPK in donor cells. Western blot analysis revealed that p38 MAPK protein expression was effectively reduced in cells transfected with p38 MAPK-targeting siRNA. Donor cells transfected with control mock siRNA or p38 MAPK siRNA were exposed to gemcitabine for $24 \mathrm{~h}$, and exosomes were purified as described in the Materials and Methods. Recipient cells were treated with exosomes for $48 \mathrm{~h}$, and cell proliferation was analyzed by WST assay. Data are presented as the mean \pm standard deviation of independent experiments in triplicate. Significantly different at $* p<0.05$ and $* * p<0.01$. CONT: Control.

that p38 MAPK was inhibited by NAC; therefore, gemcitabine stimulated p38 MAPK signalling through DNA damage-induced oxidative stress.

The present findings illustrated that treatment with exosomes purified from cells treated with genotoxic agents significantly increased cell proliferation, and these effects were blocked by chemical inhibitors of exosome biosynthesis/secretion, p38 MAPK inhibitors, and siRNA-mediated p38 MAPK silencing, highlighting the key role of p38 MAPK in exosome-mediated cell proliferation. Further analysis demonstrated that short-term treatment with exosomes in the presence of SB203580 did not block p38 MAPK phosphorylation, indicating that p38 MAPK signals can be transmitted from donor cells to recipient cells via exosomes. SB203580 is a chemical agent that strongly inhibits p38 MAPK catalytic activity without preventing its upstream kinase-mediated phosphorylation (31). Therefore, it is likely that p38 MAPK phosphorylation in exosome-treated cells resulted from transmission of the phosphoprotein, rather than the transduction of protein phosphorylation.

Exosomes contain a multitude of molecules including proteins and nucleic acids, and they are being recognized as key players in cell-cell communication (32). Only a few reports have examined the role of exosomes in tumour repopulation, and most studies were limited to observing the effect of 
A

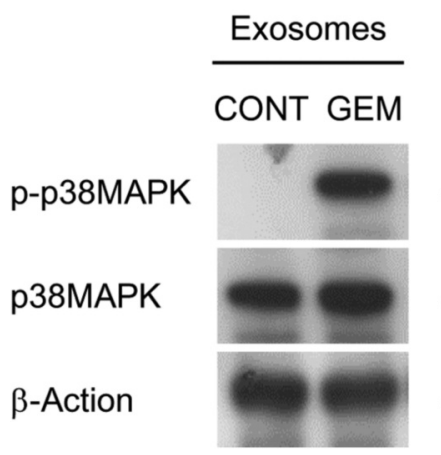

$43 \mathrm{kDa}$

$40 \mathrm{kDa}$

$42 \mathrm{kDa}$
B

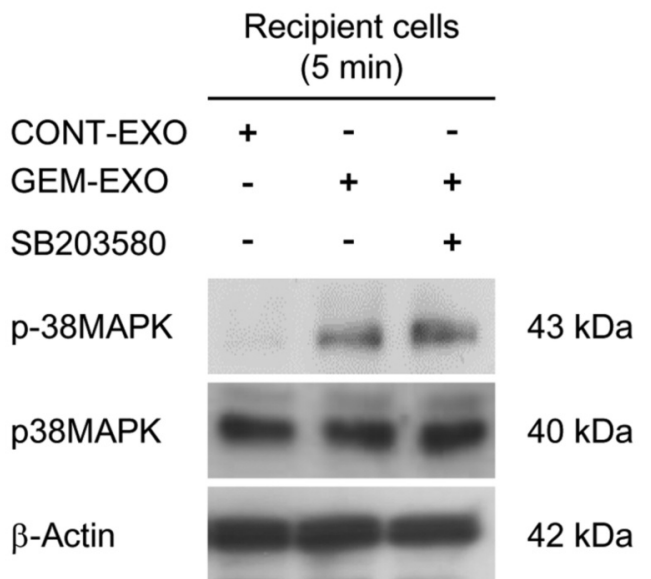

C

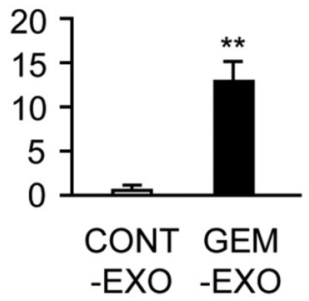

Recipient cells (2 h)

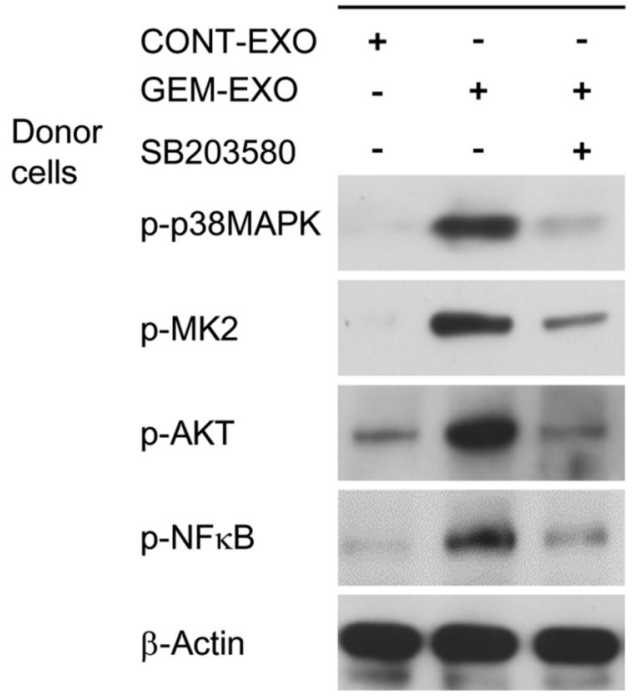

$43 \mathrm{kDa}$

$49 \mathrm{kDa}$

$60 \mathrm{kDa}$

$65 \mathrm{kDa}$

$42 \mathrm{kDa}$

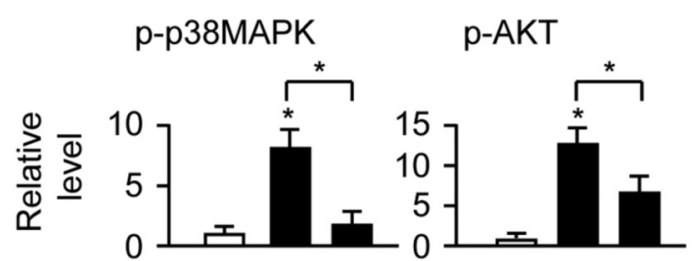

p-MK2

$p-N F \kappa B$

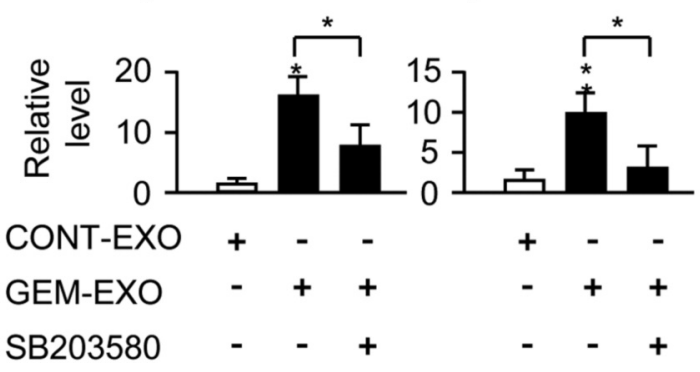

Figure 5. Exosomes carry phosphorylated (p) p38 mitogen-activated protein kinase (MAPK) protein as cargo. A: Western blot analysis of exosomes from control (CONT) and gemcitabine (GEM)-treated cells. B: Western blot analysis of p38 MAPK expression in recipient cells. Recipient cells were treated with exosomes for a short period (5 min) with or without pretreatment with SB203580 (a p38MAPK inhibitor). C: Western blot analysis of p38 MAPK downstream molecules in recipient cells. Donor cells were treated with gemcitabine for 24 hith or without pretreatment with SB203580. Cells were washed and cultured in fresh medium for $24 \mathrm{~h}$, and then exosomes were purified. Recipient cells were treated with donor cell-derived exosomes for $2 \mathrm{~h}$. Columns present the normalized band intensities relative to $\beta$-actin bands based on fold changes relative to control samples. Data are presented as the mean \pm standard deviation of three independent experiments. Significantly different at: *p<0.05 and $* * p<0.01$. AKT: AKT serine/threonine kinase 1; MK2: MAPK-activated protein kinase 2; NF-кB: nuclear factor kappa $B$. 
A
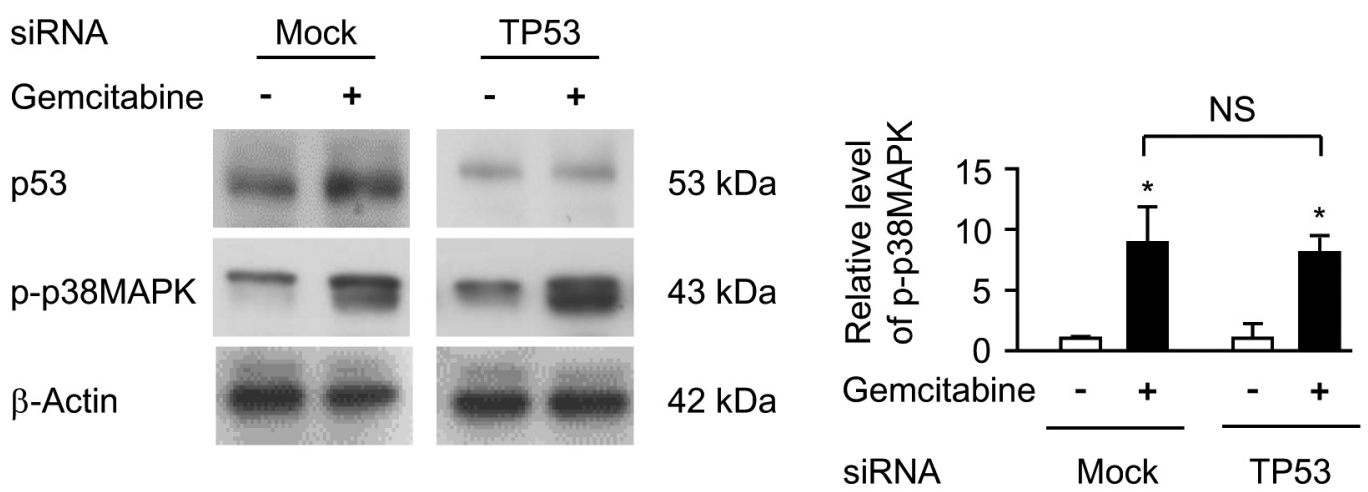

B

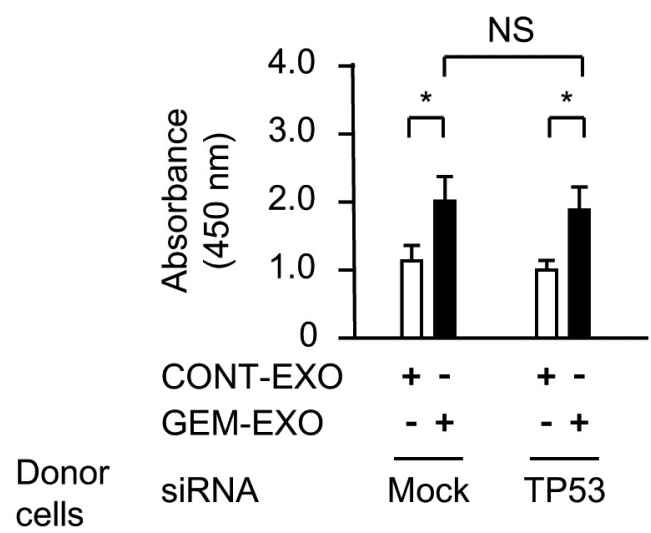

Figure 6. Gemcitabine induces 338 mitogen-activated protein kinase (MAPK) phosphorylation through a p53-independent pathway. A: Western blot analysis of p38 MAPK expression. HuCCT1 cells were transfected with mock siRNA or TP53-targeting siRNA and exposed to gemcitabine for 2 h. Columns present the normalized band intensities relative to $\beta$-actin bands based on fold changes relative to control samples. B: WST assay. Recipient HuCCT1 cells were treated with exosomes purified from gemcitabine-treated (GEM-EXO) mock siRNA- or TP53 siRNA-transfected cells for 48 h. Columns present the mean optical density at $450 \mathrm{~nm}$. Data are presented as the mean \pm standard deviation of independent experiments in triplicate. NS: Not significant; *Significantly different at $p<0.05$ vs. CONT-EXO.

exosomal circular RNA or microRNA $(19,33)$. In this study, we found that exosomes released from gemcitabine-treated cells carried phosphorylated p38 MAPK as cargo. Exosometransmitted p38 MAPK might be bioactive because long-term treatment $(2 \mathrm{~h})$ with these exosomes resulted in the activation of p38 MAPK as well as its downstream signals MAPKAPK2, AKT, and NF-kB $(34,35)$, whereas this effect was abrogated by SB203580 treatment of exosome source cells.

Our results are intriguing because p38 MAPK signalling has generally been reported to be involved in DNA damage-induced cell death (36). It should be noted that several studies reported the involvement of p38 MAPK in the proliferation in certain cancer cells (37-39). Although the contradictory evidence for the role of p38 MAPK remains to be resolved, recent studies suggested that p38 MAPK might be a third effector in the response to DNA damage in addition to ATM/checkpoint kinase 2 (CHK2) and ATR/CHK1 pathways (40). More importantly, p38 MAPK signalling has been reported to play a critical role in cell survival or proliferation, especially in the absence of functional TP53 $(41,42)$. It has been reported that p38 MAPK stimulates proliferative pathways in TP53-mutated breast cancer cells through cyclic AMP-dependent transcription factor-2 and MAPKAPK2 (42). Our data support this report by demonstrating that MAPKAPK2 phosphorylation was significantly increased by of exosomes from gemcitabine-treated cells in TP53-mutated HuCCT1 cells.

In this study, we used two types of BDC cells carrying TP53mutation. HuCCT1 cells carry a gain-of-function mutation in TP53 (R175H), a hotspot mutation with demonstrated oncogenic effects in many types of cancer (20). HuH28 cells carry an inactivating mutation in TP53 $(\mathrm{E} 271 \mathrm{~K})$, which results in loss of function because of inactivation of the DNA-binding domain (21). To address the involvement of gain-of-function activities of mutant TP53, we silenced TP53 in HuCCT1 cells using siRNA, observing no effect on p38 MAPK phosphorylation or cell proliferation. These data indicated that mutant TP53 is not involved in exosome-mediated cell proliferation. 

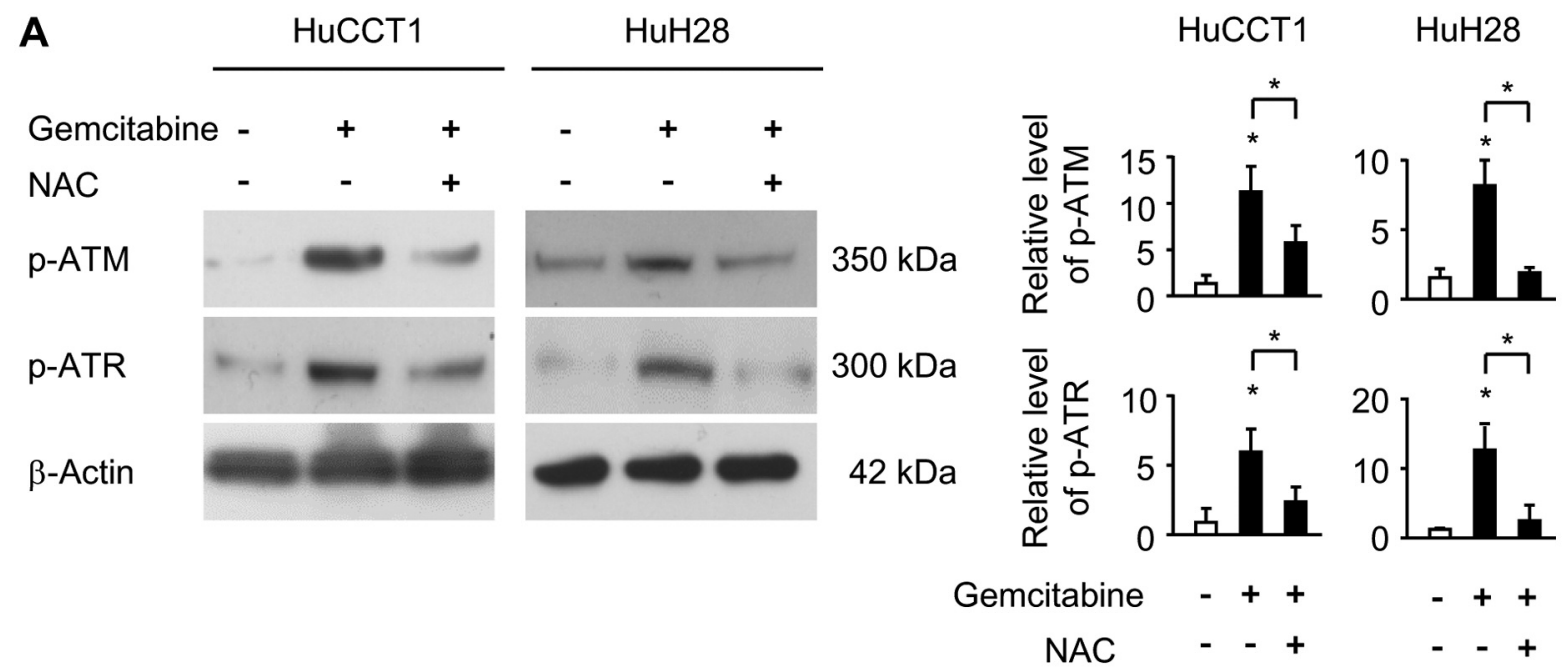

B

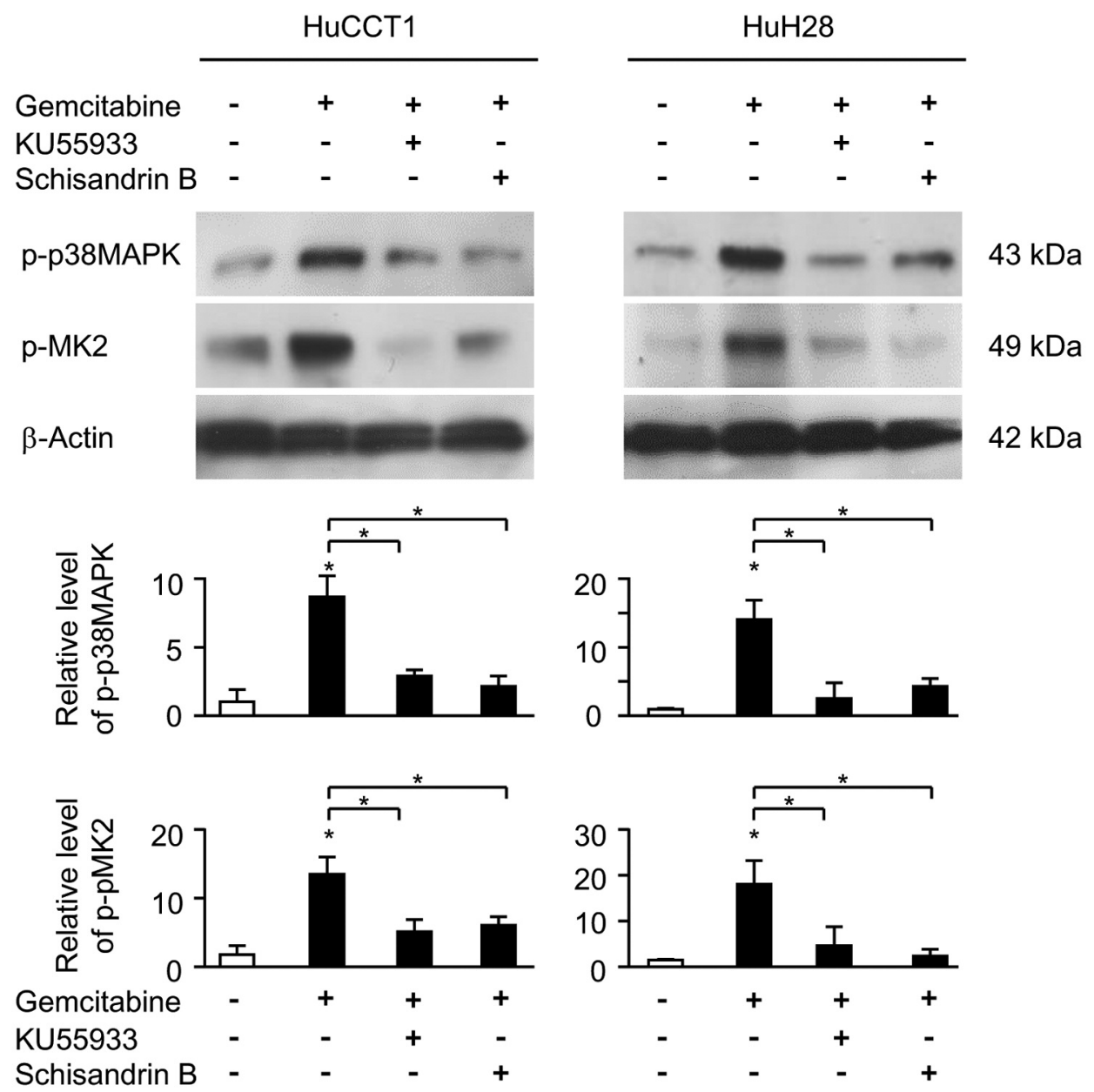

Figure 7. Gemcitabine activates p38 mitogen-activated protein kinase (MAPK) signalling through oxidative stress-induced ataxia telangiectasia and RAD3-related (ATR)-ataxia telangiectasia mutated (ATM) signalling. A: Western blot analyses of phospho ( $p$ ) ATR and p-ATM expression. Cells were treated with gemcitabine for $2 \mathrm{~h}$ with or without pretreatment with the antioxidant $N$-acetyl-L-cysteine (NAC). B: Western blot analysis of p38 MAPK downstream signalling molecules. Cells were treated with gemcitabine for $2 \mathrm{~h}$ in the presence of KU55933 (an inhibitor of ATM) or schisandrin B (an inhibitor of ATR). Columns present the normalized band intensities relative to $\beta$-actin bands based on fold changes relative to control samples. Data are presented as the mean \pm standard deviation of independent experiments in triplicate. * Significantly different at $p<0.05$ vs. control/other treatment. MK2: MAPK-activated protein kinase 2. 
To identify the upstream signals of p38 MAPK, we examined the correlation between ATM and ATR, which are the main checkpoint molecules for DNA damage. ATM and ATR phosphorylation was significantly increased by gemcitabine in both cell types in this study, and this effect was inhibited by pretreatment with NAC. Phosphorylation of p38 MAPK and its downstream molecule MAPKAPK2 was inhibited by ATM or ATR inhibitors. Taken together, it appears that exosomal p38 MAPK is primarily involved in oxidative stress-induced ATMATR signalling in a TP53-independent manner.

In conclusion, we found that gemcitabine-treated BDC cells secrete exosomes carrying a considerable amount of phosphorylated p38 MAPK as cargo, and these exosomes significantly induce cell proliferation. The mechanism by which p38 MAPK stimulates cell proliferation is unclear. As reported in recent studies $(41,42)$, the TP53 status might play a key role in determining the activities of p38 MAPK. To date, there are no efficient therapies for preventing tumour recurrence according to the TP53 status despite the high mutation rate of TP53 in human cancer, including BDC. We propose that regulating exosomal p38 MAPK might be a useful strategy for suppressing tumour repopulation in TP53-mutated cancer. In consideration of the diversity of p38 MAPK signalling, further studies in experimental animal models should be conducted.

\section{Conflicts of Interest}

The Authors declare that they have no conflicts of interest regarding this study.

\section{Authors' Contributions}

MO and YM designed the project, carried out the experiments and analyzed the data. All Authors were involved in data interpretation, YM prepared the Figures and wrote the article. JS and TW reviewed and revised the article. The final version of the article was read and approved by all of the Authors.

\section{Acknowledgements}

This work was supported in part by KAKENHI grant from the Japan Society for the Promotion of Science (JSPS) (No, 19K08365).

\section{References}

1 Tubiana M: Repopulation in human tumors. A biological background for fractionation in radiotherapy. Acta Oncol 27(2): 83-88, 1988. PMID: 3291903. DOI: 10.3109/02841868809090328

2 Jiang MJ, Gu DN, Dai JJ, Huang Q and Tian L: Dark side of cytotoxic therapy: Chemoradiation-induced cell death and tumor repopulation. Trends Cancer 6(5): 419-431, 2020. PMID: 32348737. DOI: 10.1016/j.trecan.2020.01.018

3 Chan KS: Molecular pathways: Targeting cancer stem cells awakened by chemotherapy to abrogate tumor repopulation. Clin Cancer Res 22(4): 802-806, 2016. PMID: 26671994. DOI: 10.1158/1078-0432.CCR-15-0183
4 Lee HS, Lee SH, Roh YH, Chung MJ, Park JY, Park SW, Song SY, Chung JB and Bang S: Efficacy of adjuvant chemotherapy and prognostic factors for patients with extrahepatic bile duct cancer. Chemotherapy 61(3): 152-158, 2016. PMID: 26788726. DOI: $10.1159 / 000441377$

5 Skipworth JR, Keane MG and Pereira SP: Update on the management of cholangiocarcinoma. Dig Dis 32(5): 570-578, 2014. PMID: 25034290. DOI: 10.1159/000360507

6 Ryoo HD, Gorenc T and Steller H: Apoptotic cells can induce compensatory cell proliferation through the JNK and the Wingless signaling pathways. Dev Cell 7(4): 491-501, 2004. PMID: 15469838. DOI: 10.1016/j.devcel.2004.08.019

7 Fan Y and Bergmann A: Apoptosis-induced compensatory proliferation. The Cell is dead. Long live the Cell! Trends Cell Biol 18(10): 467-473, 2008. PMID: 18774295 . DOI: $10.1016 /$ j.tcb.2008.08.001

8 Fan Y and Bergmann A: Distinct mechanisms of apoptosis-induced compensatory proliferation in proliferating and differentiating tissues in the Drosophila eye. Dev Cell 14(3): 399-410, 2008. PMID: 18331718. DOI: 10.1016/j.devcel.2008.01.003

9 Friedman R: Drug resistance in cancer: molecular evolution and compensatory proliferation. Oncotarget 7(11): 11746-11755, 2016. PMID: 26909596. DOI: 10.18632/oncotarget.7459

10 Fogarty CE and Bergmann A: Killers creating new life: caspases drive apoptosis-induced proliferation in tissue repair and disease. Cell Death Differ 24(8): 1390-1400, 2017. PMID: 28362431. DOI: $10.1038 / \mathrm{cdd} .2017 .47$

11 Martín FA, Peréz-Garijo A and Morata G: Apoptosis in Drosophila: compensatory proliferation and undead cells. Int $\mathbf{J}$ Dev Biol 53(8-10): 1341-1347, 2009. PMID: 19247932. DOI: 10.1387/ijdb.072447fm

12 Simón R, Aparicio R, Housden BE, Bray S and Busturia A: Drosophila p53 controls Notch expression and balances apoptosis and proliferation. Apoptosis 19(10): 1430-1443, 2014. PMID: 24858703. DOI: 10.1007/s10495-014-1000-5

13 Zhao M, Wang Y, Zhao Y, He S, Zhao R, Song Y, Cheng J, Gong Y, Xie J, Wang Y, Hu B, Tian L and Huang Q: Caspase-3 knockout attenuates radiation-induced tumor repopulation via impairing the ATM/p53/Cox-2/PGE 2 pathway in non-small cell lung cancer. Aging (Albany NY) 12(21): 21758-21776, 2020. PMID: 33180744. DOI: 10.18632/aging.103984

14 Nakamura H, Arai Y, Totoki Y, Shirota T, Elzawahry A, Kato M, Hama N, Hosoda F, Urushidate T, Ohashi S, Hiraoka N, Ojima H, Shimada K, Okusaka T, Kosuge T, Miyagawa S and Shibata T: Genomic spectra of biliary tract cancer. Nat Genet 47(9): 1003-1010, 2015. PMID: 26258846. DOI: 10.1038/ng.3375

15 Noguchi R, Yamaguchi K, Ikenoue T, Terakado Y, Ohta Y, Yamashita N, Kainuma O, Yokoi S, Maru Y, Nagase H and Furukawa Y: Genetic alterations in Japanese extrahepatic biliary tract cancer. Oncol Lett 14(1): 877-884, 2017. PMID: 28693246. DOI: $10.3892 / \mathrm{ol} .2017 .6224$

$16 \mathrm{Wu}$ CE, Pan YR, Yeh CN and Lunec J: Targeting P53 as a future strategy to overcome gemcitabine resistance in biliary tract cancers. Biomolecules 10(11): 1474, 2020. PMID: 33113997. DOI: $10.3390 /$ biom 10111474

17 Sokolov MV and Neumann RD: Radiation-induced bystander effects in cultured human stem cells. PLoS One 5(12): e14195, 2010. PMID: 21152027. DOI: 10.1371/journal.pone.0014195

18 Zhang Z, Feng X, Deng Z, Cheng J, Wang Y, Zhao M, Zhao Y, $\mathrm{He} S$ and Huang Q: Irradiation-induced polyploid giant cancer cells are involved in tumor cell repopulation via neosis. Mol 
Oncol 15(8): 2219-2234, 2021. PMID: 33523579. DOI: 10.1002/1878-0261.12913

19 Jiang MJ, Chen YY, Dai JJ, Gu DN, Mei Z, Liu FR, Huang Q and Tian L: Dying tumor cell-derived exosomal miR-194-5p potentiates survival and repopulation of tumor repopulating cells upon radiotherapy in pancreatic cancer. Mol Cancer 19(1): 68, 2020. PMID: 32228703. DOI: 10.1186/s12943-020-01178-6

20 Chiang YT, Chien YC, Lin YH, Wu HH, Lee DF and Yu YL: The function of the mutant p53-R175H in cancer. Cancers (Basel) 13(16): 4088, 2021. PMID: 34439241. DOI: 10.3390/cancers 13164088

21 Kato S, Han SY, Liu W, Otsuka K, Shibata H, Kanamaru R and Ishioka $\mathrm{C}$ : Understanding the function-structure and functionmutation relationships of $\mathrm{p} 53$ tumor suppressor protein by highresolution missense mutation analysis. Proc Natl Acad Sci USA 100(14): 8424-8429, 2003. PMID: 12826609. DOI: 10.1073/ pnas. 1431692100

22 Okamoto K, Miyoshi K and Murawaki Y: miR-29b, miR-205 and miR-221 enhance chemosensitivity to gemcitabine in $\mathrm{HuH} 28$ human cholangiocarcinoma cells. PLoS One 8(10): e77623, 2013. PMID: 24147037. DOI: 10.1371/journal.pone.0077623

23 Kariba Y, Yoshizawa T, Sato Y, Tsuyama T, Araki E and Yamagata $\mathrm{K}$ : Brown adipocyte-derived exosomal miR-132-3p suppress hepatic Srebf1 expression and thereby attenuate expression of lipogenic genes. Biochem Biophys Res Commun 530(3): 500-507, 2020. PMID: 32595040 . DOI: 10.1016/j.bbrc.2020.05.090

24 Thonsri U, Seubwai W, Waraasawapati S, Wongkham S, Boonmars T, Cha'on U and Wongkham C: Antitumor effect of shikonin, a PKM2 inhibitor, in cholangiocarcinoma cell lines. Anticancer Res 40(9): 5115-5124, 2020. PMID: 32878800. DOI: 10.21873/anticanres.14515

25 Sato H, Hiraki M, Namba T, Egawa N, Baba K, Tanaka T and Noshiro H: Andrographolide induces degradation of mutant p53 via activation of Hsp70. Int J Oncol 53(2): 761-770, 2018 PMID: 29845212. DOI: 10.3892/ijo.2018.4416

26 Zhang M, Das C, Vasquez H, Aguilera D, Zage PE, Gopalakrishnan V and Wolff JE: Predicting tumor cell repopulation after response: mathematical modeling of cancer cell growth. Anticancer Res 26(4B): 2933-2936, 2006. PMID: 16886616.

27 Withers HR: Treatment-induced accelerated human tumor growth. Semin Radiat Oncol 3(2): 135-143, 1993. PMID: 10717064. DOI: $10.1054 /$ SRAO00300135

28 Feng X, Yu Y, He S, Cheng J, Gong Y, Zhang Z, Yang X, Xu B, Liu X, Li CY, Tian L and Huang Q: Dying glioma cells establish a proangiogenic microenvironment through a caspase 3 dependent mechanism. Cancer Lett 385: 12-20, 2017. PMID: 27826040. DOI: 10.1016/j.canlet.2016.10.042

29 Cheng J, He S, Wang M, Zhou L, Zhang Z, Feng X, Yu Y, Ma J, Dai C, Zhang S, Sun L, Gong Y, Wang Y, Zhao M, Luo Y, Liu $\mathrm{X}$, Tian L, Li C and Huang Q: The caspase-3/PKCס/Akt/VEGFA signaling pathway mediates tumor repopulation during radiotherapy. Clin Cancer Res 25(12): 3732-3743, 2019. PMID: 30890550. DOI: 10.1158/1078-0432.CCR-18-3001

30 McCubrey JA, Lahair MM and Franklin RA: Reactive oxygen species-induced activation of the MAP kinase signaling pathways. Antioxid Redox Signal 8(9-10): 1775-1789, 2006. PMID: 16987031. DOI: 10.1089/ars.2006.8.1775

31 Kumar S, Jiang MS, Adams JL and Lee JC: Pyridinylimidazole compound SB 203580 inhibits the activity but not the activation of p38 mitogen-activated protein kinase. Biochem Biophys Res
Commun 263(3): 825-831, 1999. PMID: 10512765. DOI: 10.1006/bbrc. 1999.1454

32 Campos A, Sharma S, Obermair A and Salomon C: Extracellular vesicle-associated miRNAs and chemoresistance: a systematic review. Cancers (Basel) 13(18): 4608, 2021. PMID: 34572835. DOI: $10.3390 /$ cancers 13184608

33 Chen YY, Jiang MJ and Tian L: Analysis of exosomal circRNAs upon irradiation in pancreatic cancer cell repopulation. BMC Med Genomics 13(1): 107, 2020. PMID: 32727565. DOI: 10.1186/s12920-020-00756-3

34 Papermaster DS, Schneider BG and Besharse JC: Vesicular transport of newly synthesized opsin from the Golgi apparatus toward the rod outer segment. Ultrastructural immunocytochemical and autoradiographic evidence in Xenopus retinas. Invest Ophthalmol Vis Sci 26(10): 1386-1404, 1985. PMID: 2931395.

35 Hommerich CP: Ototoxicity of loop diuretics. Morphological and electrophysiological examinations in animal experiments. Adv Otorhinolaryngol 44: 92-164, 1990. PMID: 2407070.

36 Tyagi M, Bhattacharyya R, Bauri AK, Patro BS and Chattopadhyay S: DNA damage dependent activation of checkpoint kinase-1 and mitogen-activated protein kinase-p38 are required in malabaricone $\mathrm{C}$-induced mitochondrial cell death. Biochim Biophys Acta 1840(3): 1014-1027, 2014. PMID: 24291689. DOI: $10.1016 /$ j.bbagen.2013.11.020

37 Cheng J, Tian L, Ma J, Gong Y, Zhang Z, Chen Z, Xu B, Xiong H, Li C and Huang Q: Dying tumor cells stimulate proliferation of living tumor cells via caspase-dependent protein kinase $\mathrm{C} \delta$ activation in pancreatic ductal adenocarcinoma. Mol Oncol 9(1): 105-114, 2015. PMID: 25156550. DOI: 10.1016/j.molonc. 2014.07.024

38 Zhang Z, Rui W, Wang ZC, Liu DX and Du L: Anti-proliferation and anti-metastasis effect of barbaloin in non-small cell lung cancer via inactivating p38MAPK/Cdc25B/Hsp27 pathway. Oncol Rep 38(2): 1172-1180, 2017. PMID: 28656293. DOI: 10.3892/or.2017.5760

39 Wang Y, Shang K, Zhang N, Zhao J and Cao B: Tumor-associated macrophage-derived exosomes promote the progression of gastric cancer by regulating the P38MAPK signaling pathway and the immune checkpoint PD-L1. Cancer Biother Radiopharm, 2021. PMID: 34698510. DOI: 10.1089/cbr.2021.0218

40 Reinhardt HC and Yaffe MB: Kinases that control the cell cycle in response to DNA damage: Chk1, Chk2, and MK2. Curr Opin Cell Biol 21(2): 245-255, 2009. PMID: 19230643. DOI: 10.1016/j.ceb.2009.01.018

41 Reinhardt HC, Aslanian AS, Lees JA and Yaffe MB: p53deficient cells rely on ATM- and ATR-mediated checkpoint signaling through the $\mathrm{p} 38 \mathrm{MAPK} / \mathrm{MK} 2$ pathway for survival after DNA damage. Cancer Cell 11(2): 175-189, 2007. PMID: 17292828. DOI: 10.1016/j.ccr.2006.11.024

42 Chen L, Mayer JA, Krisko TI, Speers CW, Wang T, Hilsenbeck SG and Brown PH: Inhibition of the p38 kinase suppresses the proliferation of human ER-negative breast cancer cells. Cancer Res 69(23): 8853-8861, 2009. PMID: 19920204. DOI: 10.1158/0008-5472.CAN-09-1636

Received November 17, 2021

Revised December 7, 2021

Accepted December 9, 2021 